\title{
The Structural Analysis of MWCNTs Modified by DBD Plasma and Electrical Properties on Schottky Diode Application
}

\author{
Norain Sahari ${ }^{1}$, Zolkafle Buntat ${ }^{2}$, Zulkifli Azman ${ }^{3}$, Zuraidah Ngadiron $^{1}$, Sim Sy Yi ${ }^{1}$, Nor Aira Zambri ${ }^{1}$, \\ Faridah Hanim Mohd Noh ${ }^{1}$, Farahiyah Mustafa ${ }^{1}$, Sumaiya Mashori ${ }^{1}$, Rasida Norjali ${ }^{1}$ \\ ${ }^{1}$ Faculty of Engineering Technology, University Tun Hussein Onn Malaysia (UTHM), \\ norains@uthm.edu.my, zuraidahn@uthm.edu.my, sysim@uthm.edu.my, aira@uthm.edu.my, \\ hanim@uthm.edu.my, farahiyah@uthm.edu.my, sumaiya@uthm.edu.my, rasida@uthm.edu.my \\ ${ }^{2}$ Institute of High Voltage and High Current, University Teknologi Malaysia (UTM), \\ zolkafle@utm.my \\ ${ }^{3}$ Faculty of Electrical and Electronic, University Tun Hussein Onn Malaysia (UTHM), \\ zulkifli.bin.azman@gmail.com
}

\begin{abstract}
Metallic nature of multiwalled carbon nanotubes (MWCNTs) were modified using low frequency $(50 \mathrm{~Hz})$ non-equilibrium plasma, which was generated separately by oxygen and nitrogen dielectric barrier discharge plasma (DBD) at atmospheric pressure. Its potential to behave as semiconducting behavior mainly in diode application was studied. The surface structure and electrical properties changes before and after treatments were analyzed by using X-Ray Photoelectron (XPS), and IV measurement (a two-point probe). The current-voltage $(I-V)$ characteristics shows that $\mathrm{Au} / \mathrm{MWCNT}-\mathrm{N}_{2}(12 \mathrm{kV}) / \mathrm{Al}$ shows good rectifying behavior. This showed that, the nitrogen-containing group can modify the metallic nature of MWCNTs to semiconducting behavior. Since the I-V curves for $\mathrm{Au} / \mathrm{MWCNTs} \mathrm{N}_{2}(12 \mathrm{kV}) / \mathrm{Al}$ has rectifying behavior similar to Schottky diode, the electronic parameters such as ideality factor, barrier height and series resistance of the device were extracted by using three methods and give good agreement between them.
\end{abstract}

Key words : DBD plasma; metallic; semiconducting; Schottky diode

\section{INTRODUCTION}

Schottky diodes playing an important role in recent electronics technology. Schottky diodes are the fundamental of the large number compound semiconductor device although they have the simplest structure [1]. Among their unique advantages over $\mathrm{p}$-n junction diodes are fast response, low resistance and small transient reverse current during switching $[2,3]$. CNTs are an excellent candidate nowadays due to several reasons which are near ballistic transport and making them a very low-power alternative $[4,5]$. One foremost obstacle to the implementation of CNTs in electronic devices is the present of metallic tubes in bulk SWCNTs. Generally, as-grown SWCNTs consist of one third metallic tubes and the remains are semiconducting

[6]. On the other hand, bulk MWCNTs have metallic behavior due to their large diameter and complex structure of each tubes [7]. However, the application of micro and nano-electronic devices especially like Schottky diode or transistor, semiconducting CNT are required [8].

A variety different methods to separate metallic and semiconducting SWCNTs has been implemented such as ac-dielectrophoresis [9], selective breakdown of metallic SWCNTs [10], DNA wrapping [11], gel agarose electrophoresis [12] and amine extraction [13]. Up to now, the manufacture of semiconducting CNTs on a bulk scale is still a challenging process. Besides, the production of SWCNTs is expensive and complex as compared to MWCNTs that can be produced on a large scale with a reasonable price [14]. Regarding to this issue, the modification of MWCNTs properties to ensure that they can be a semiconducting behavior needs further exploration. Previously, the transition of metallic MWCNTs into semiconducting one by burning or removing the outer carbon shells via electrical breakdown has been proposed by Collin et al. [15]. However, this technique can cause parallel breakdown and might destroy CNT devices due to uncontrolled method.

Recently, studies on modification of MWCNTs properties based on defect and imperfections could recommend a possible route to alter their electronic properties. Activated v-CNT tips from MWCNTs doped with nitrogen to tune their electronic properties has been reported by Mattia et al. [16]. Janas et al. modified MWCNTs electronic nature by exposed the CNT nanotube films to vapors from harsh chemicals [17]. 
Their electronics properties also can be changed by the replacement of carbon atoms with boron dopants [18] and an oxidizing agent [19]. Besides that, numerous approaches has been stabilized to change the electronic properties of MWCNTs such as polymer wrapping [20], fluorination [21], electrochemical methods [22] and plasma treatment [23].

Plasma treatment offers some worthwhile advantages, including short time treatment, the capability to be processed at room temperature and environmentally friendly process. Depending on the plasma parameters, such as applied voltage, plasma gas used, time treatment, and the power and frequency of the plasma different defect structures and functional groups can be formed on the CNT surface. The $\mathrm{C}=\mathrm{C}$ bond of $\mathrm{CNT}$ is attacked by the excited molecules and it generates radicals during plasma discharge. This process produces open ends and defect sites as the main sites for functionalization. Dielectric barrier discharge (DBD) plasma is the most flexible and simplest plasma amongst the different methods used to produce a plasma. This method is described by the presence of at most one dielectric barrier in contact with the discharge between two electrodes connected to a high voltage power supply.

In this study, defects on MWCNTs surface by using atmospheric pressure DBD plasma treatment at $50 \mathrm{~Hz}$ were produced. The purpose of this research is to study the probability of altering the electronic properties of metallic MWCNT by DBD treatments by using two different gases at atmospheric pressure. Changes in the structural surface and electrical properties that appeared on the MWCNTs after the treatments were examined by using XPS and IV measurement (a two-point probe). The Au/Treated MWCNTs/Al Schottky diode was fabricated and their performance parameters were evaluated and compared to other CNTs based Schottky diodes.

\section{METHODOLOGY}

\subsection{Materials}

MWCNTs powder got commercially and prepared by Combustion Chemical Vapor Deposition (CCVD) were used without purification. The lengths were about $10-30 \mu \mathrm{m}$ and the outer and inner diameters lies between $20-30 \mathrm{~nm}$ and $5-10 \mathrm{~nm}$ respectively.

\subsection{DBD Apparatus}

Figure 1 shows the experimental set-up of DBD plasma discharge used in this work that conducted in ambient air. Two gases which are oxygen and nitrogen were used separately as a buffer gas. Discharges were produced between $60 \mathrm{~mm}$ diameter of two circular plane parallel copper electrodes. In the case of DBD, both electrodes were enclosed by a $2 \mathrm{~mm}$ thick glass material that acted as a dielectric barrier which permits the charge build up and maintains the plasma from micro discharge. A fine wire mesh (\#325) was inserted between the electrode and the glass so that a stable glow discharge can be obtained. In both cases (oxygen and nitrogen), the gap spacing, gas flow rate and time treatment were kept constant at $2 \mathrm{~mm}, 1 \mathrm{lpm}$ and 10 minutes, respectively. A voltage between 1 to $20 \mathrm{kV}$ at a frequency of $50 \mathrm{~Hz}$ was used as the voltage supply.

A high voltage probe (Tektronix P6015A, 1000x) was used to measure the voltage applied to the electrodes. The discharge current was determined by using a Pearson Rogowski current monitor via a $50 \Omega$ resistor connected in series to the ground. The PicoScope 5242A was used to record the waveform of the applied voltage and discharge current.

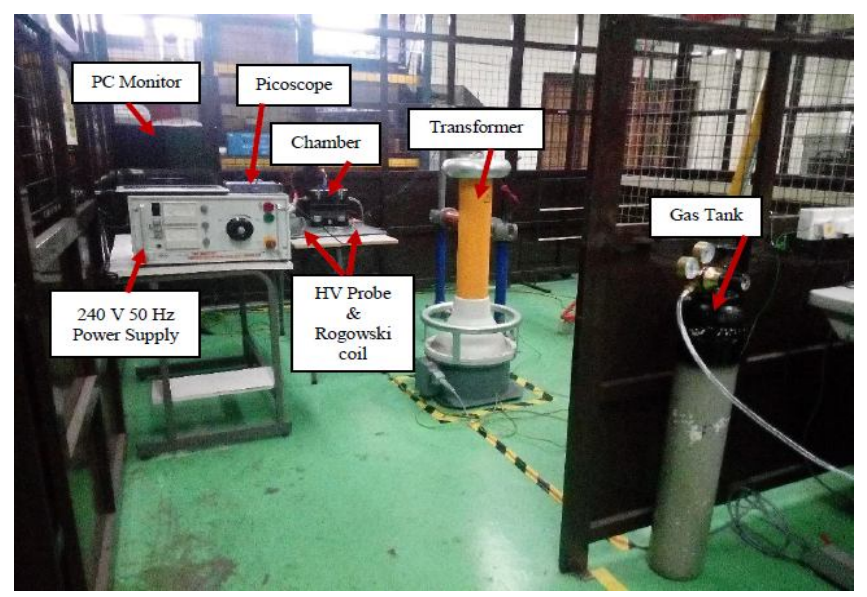

Figure 1: Apparatus setup for DBD plasma treatment

\subsection{Thin Film Fabrication}

The MWCNTs thin film was fabricated on glass substrate, by using drop casting method. $0.6 \mathrm{mg}$ of treated and untreated MWCNTs powders at different gas sources and different plasma voltages, was dissolved in $60 \mathrm{~mL}$ DI water, sonicated for 2 hours and stirred for $6 \mathrm{~h}$ to get a uniform solution. Then, same volume of each MWCNTs solution was dropped on a cleaned glass substrate by using micropipette so that a similar thickness of thin film for all samples can be achieved. Finally, the DI water for all samples were evaporated by baked at 100 ${ }^{\mathrm{o}} \mathrm{C}$.

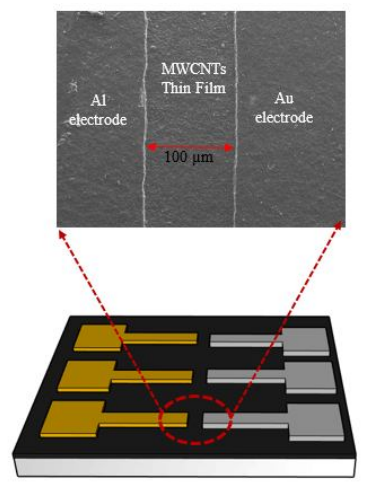

Figure 2: Cross-sectional view of $\mathrm{Al} / \mathrm{MWCNTs} / \mathrm{Au}$ surface type Schottky diode 
Two asymmetrical electrodes, which are Gold (Au) and Aluminium (Al), were contacted at two ends of the MWCNTs thin film by using thermal evaporator. Au and $\mathrm{Al}$ were chosen as contacts owing to their high and low work functions that can act as Ohmic contact and rectifying contact, respectively. In a previous work, the combination of these two electrodes was shown to rectify the current when semiconducting SWCNT was contacting between Al and Au metals [24]. Our main aim was to reach a similar rectifying behavior by using a treated MWCNTs network. Figure 2 displays the FESEM image of thin film between $100 \mu \mathrm{m} \mathrm{Al}$ and $\mathrm{Au}$ electrodes. After completion the fabrication of thin film and deposition of asymmetric electrodes, this device can be called as $\mathrm{Au} / \mathrm{MWCNTs} / \mathrm{Al}$ surface type of Schottky diode.

\subsection{Materials Characterization}

Materials characterizations were carried out in two forms, which were in powder and thin film forms. The powder form of MWCNTs was used for characterization using XPS Spectroscopy. Thin films of pristine and treated MWCNTs deposited with two electrodes ( $\mathrm{Al}$ and $\mathrm{Au}$ ) by using thermal evaporation were analyzed by using the current voltage (IV) measurement.

\section{X-Ray Photoelectron (XPS)}

The defect structure of the MWCNTs samples was explored using a Raman Horiba Xplora Plus. The excitation line was set to $\lambda=532 \mathrm{~nm}$ and magnification set to 40x. Detailed scans from $800 \mathrm{~cm}^{-1}$ to $2000 \mathrm{~cm}^{-1}$ were conducted on each MWCNT sample.

\section{Current-Voltage (IV) Measurement}

The IV characteristics were conducted using a Keithley 6517B source metre to investigate the Ohmic or Schottky behavior of CNTs between the asymmetrical electrodes ( $\mathrm{Al}$ and $\mathrm{Au})$.

\section{RESULTS AND DISCUSSIONS}

\subsection{X-Ray Photoelectron Spectroscopy (XPS)}

X-Ray photoelectron spectroscopy (XPS) was used to characterize the surface atomic composition of pristine and treated MWCNTs. The presence of carbon, oxygen and nitrogen atom that nominated by $\mathrm{C} 1 \mathrm{~s}, \mathrm{O} 1 \mathrm{~s}$ and $\mathrm{N} 1 \mathrm{~s}$ are appear at position 283.9, 531.8 and $399 \mathrm{eV}$ respectively. From Figure 3, it can be seen that the pristine MWCNT (MWCNT-p) has no N 1s signal but low oxygen levels (O 1s) were detected which arises from oxygen or water absorbed on MWCNTs. After being treated by oxygen DBD plasma treatment, the peak of $\mathrm{O} 1 \mathrm{~s}$ appears obviously for all treatment conditions. The oxygen atomic percentage can reach up to 16.9 and 32.5 at. $\%$ when treated at applied voltage of 6 and 8
$\mathrm{kV}$ respectively. At higher applied voltage, the composition of $\mathrm{O} 1 \mathrm{~s}$ decreased gradually to 28.8 at. $\%$. The carbon and oxygen atomic percent of MWCNTs for pristine and after treated by oxygen DBD plasma is tabulated in the inset of Figure 3. The XPS C 1s peak fitting for MWCNTs-p and MWCNTs- $\mathrm{O}_{2}(10 \mathrm{kV})$ are shown in Figure 4 (a) and 4 (b). In Figure 4 (a), the C 1s for MWCNTs-p can be decomposed into two components which are peak 1 at $283.9 \mathrm{eV}$ and peak 2 at $284.4 \mathrm{eV}$.

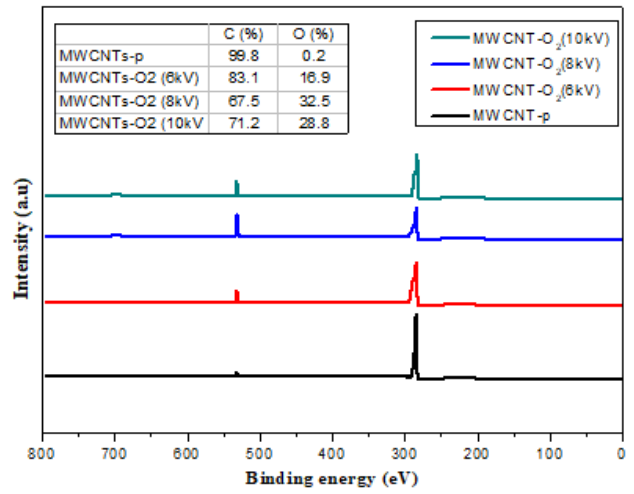

Figure 3: XPS spectra of pristine and MWCNT- $\mathrm{O}_{2}$.

The peak 1 is attributed to the $\mathrm{sp}^{2}$ type carbon which indicates the level of graphite, whereas the peak 2 corresponds to the diamond-like $\mathrm{sp}^{3}$ carbon which denotes the defects and disorder level. After plasma treatment, the functional groups which is at peak 3, 4 and 5 turn out in the $\mathrm{C} 1 \mathrm{~s}$ component. These peaks are corresponding to hydroxyl, carbonyl and carboxyl group respectively.

Table 1 displays the relative percentage of carbon atom components for MWCNT-p and MWCNT-O $\mathrm{O}_{2}$ treated at all applied voltage, after quantitative analysis.

Figure 5 shows the XPS spectra of pristine and MWCNT-N 2 . The carbon and nitrogen atomic percent of MWCNTs for pristine and after treated by nitrogen DBD plasma is tabulated in the inset of Figure 5. The presence of N 1s signal at $399 \mathrm{eV}$ after nitrogen DBD plasma treatment confirms that the incorporation of nitrogen functional group into MWCNTs surface was successful. MWCNTs- $\mathrm{N}_{2}$ treated at $10 \mathrm{kV}$ results to a moderate nitrogen content of approximately 4 at. \%. The signal of $\mathrm{N} 1 \mathrm{~s}$ increases slightly for applied voltage plasma at $12 \mathrm{kV}$ which is 14.8 at \%, but leads to decrease the nitrogen content at higher applied voltage $(14 \mathrm{kV})$ of about 10.3 at $\%$.

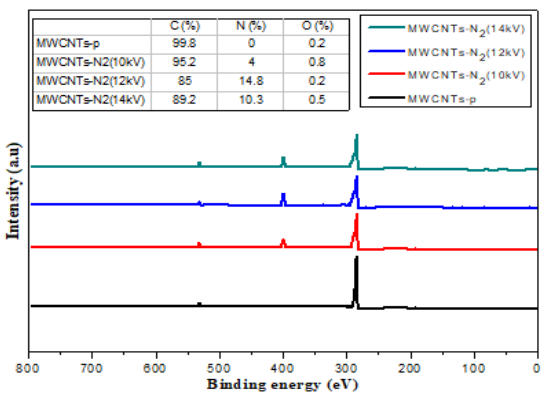

Figure 5: XPS spectra of pristine and MWCNT- $\mathrm{N}_{2}$. 


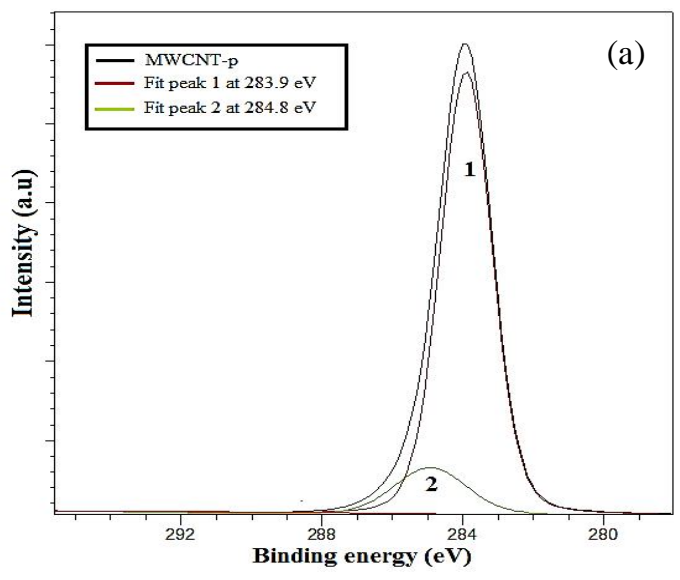

(a)

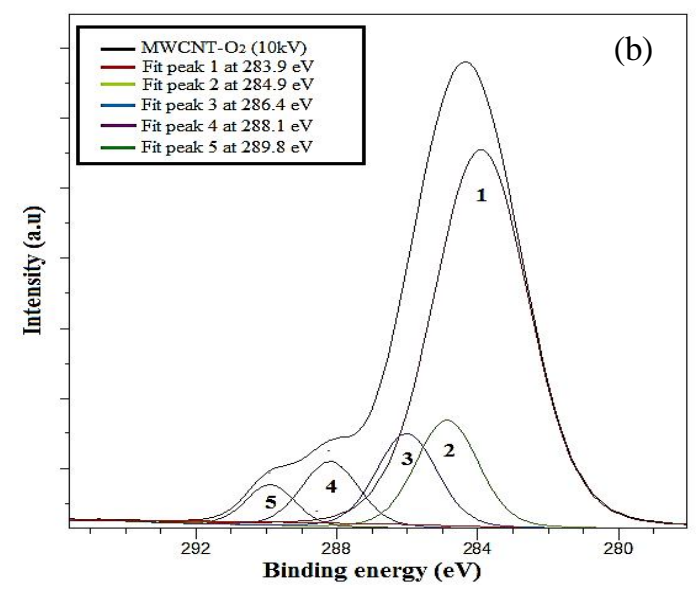

(b)

Figure 4: The XPS C 1s peak fitting for (a) MWCNT-p, (b) MWCNT-O $\mathrm{O}_{2}(10 \mathrm{kV})$

Table 1. Relative percentage of carbon atom components for MWCNT-p and MWCNT-O ${ }_{2}$ treated at all applied voltage.

\begin{tabular}{|c|c|c|c|c|c|c|c|}
\hline & $\mathrm{C}(\%)$ & $\mathrm{O}(\%)$ & Fit peak 1 & Fit peak 2 & Fit peak 3 & Fit peak 4 & Fit peak 5 \\
\hline & & & $\begin{array}{l}\mathrm{Sp}^{2} \text { carbon } \\
(\%) \text { graphite } \\
\text { like }\end{array}$ & $\begin{array}{l}\mathrm{Sp}^{3} \text { carbon } \\
(\%) \\
\text { diamond } \\
\text { like }\end{array}$ & $\begin{array}{l}\mathrm{C}-\mathrm{O} \quad(\%) \\
\text { hydroxyl } \\
\text { groups }\end{array}$ & $\begin{array}{l}\mathrm{C}=\mathrm{O} \quad(\%) \\
\text { carbonyl } \\
\text { groups }\end{array}$ & $\begin{array}{lr}\mathrm{COO} \quad(\%) \\
\text { carboxyl groups }\end{array}$ \\
\hline MWCNT-p & 99.8 & 0.2 & 86.07 & 13.93 & 0 & 0 & 0 \\
\hline $\begin{array}{l}\text { MWCNT- }{ }_{2} \\
(6 \mathrm{kV})\end{array}$ & 83.1 & 16.9 & 71.51 & 14.73 & 8.37 & 3.65 & 1.74 \\
\hline $\begin{array}{l}\text { MWCNT-O } \\
(8 \mathrm{kV})\end{array}$ & 67.5 & 32.5 & 63.15 & 12.31 & 14.78 & 7.38 & 2.38 \\
\hline $\begin{array}{l}\text { MWCNT-O } \\
(10 \mathrm{kV})\end{array}$ & 71.2 & 28.8 & 65.86 & 12.37 & 11.13 & 6.91 & 3.73 \\
\hline
\end{tabular}

Figure 6 (a) and (b) show the $\mathrm{N}$ 1s and $\mathrm{C}$ 1s peak fitting for MWCNTs- $\mathrm{N}_{2}(12 \mathrm{kV})$ respectively. As shown in Figure 6 (a), the $\mathrm{N}$ 1s peak fitting has three components indicating that the $\mathrm{N}$ atoms have three different bonding characters inserted into MWCNT network (Figure 7 (c)). The peak 2 and peak 3 located at 400.1 and $398.2 \mathrm{eV}$ are correspond to "pyrrolic" and "pyridinic" $\mathrm{N}$, respectively. They refer to the $\mathrm{N}$ atoms which are located in a $\pi$ conjugated system and contribute to the $\pi$ system with one or two p-electrons, respectively. The peak 1 at $401.7 \mathrm{eV}$ is a "graphitic" $\mathrm{N}$, which refers to the $\mathrm{N}$ atoms substituting $\mathrm{C}$ atoms inside the tubes.

For C 1s peak fitting in Figure 6 (b), the main peak at 284.0 $\mathrm{eV}$ is attributed to the graphite-like $\mathrm{sp}^{2}$ carbon. The peak 2 at $285.2 \mathrm{eV}$ can be denoted to $\mathrm{sp}^{3}$ type carbon (defect and disorder), while the other peaks at 286.1 and $287.5 \mathrm{eV}$ can result from carbon atoms bonded to either nitrogen or oxygen species. It this case, these two peaks can be correlated to C-N, $\mathrm{C}=\mathrm{N}$ and $\mathrm{CN}$ (nitrile) type bonds since the total increase of oxygen $(\mathrm{O} 1 \mathrm{~s})$ upon plasma treatment is rather low than the $\mathrm{N}$ 1s signal.
The duration of plasma treatment on MWCNTs also varied in different time in order to investigate deeply the effect on MWNCTs. Figure 7 (a) and (b) demonstrate the variation of oxygen and nitrogen concentration respectively with different applied voltage and time treatment. The concentration of oxygen and nitrogen is verified from $\mathrm{C} 1 \mathrm{~s}$ and $\mathrm{N}$ 1s bond, respectively from XPS analysis.

Based on Figure 7 (a), the concentration of oxygen is small for MWCNTs- $\mathrm{O}_{2}(6 \mathrm{kV})$ at all treatment time. However, the concentration of oxygen for MWCNTs- $\mathrm{O}_{2}(10 \mathrm{kV})$ is less than MWCNTs- $\mathrm{O}_{2}(8 \mathrm{kV})$. This is due to the different of oxygen energy bombarded to the MWCNTs surface.

Theoretically, $10 \mathrm{kV}$ applied voltage of plasma has higher electron energy than $8 \mathrm{kV}$ applied voltage. The electron energy at different applied voltage has been calculated at previous section. Thus, higher energy of oxygen bombardment only attacked the MWCNTs surface and have sufficient energy to move away from carbon atom rather than produce $\mathrm{C}=\mathrm{O}$ bond with carbon atom. 


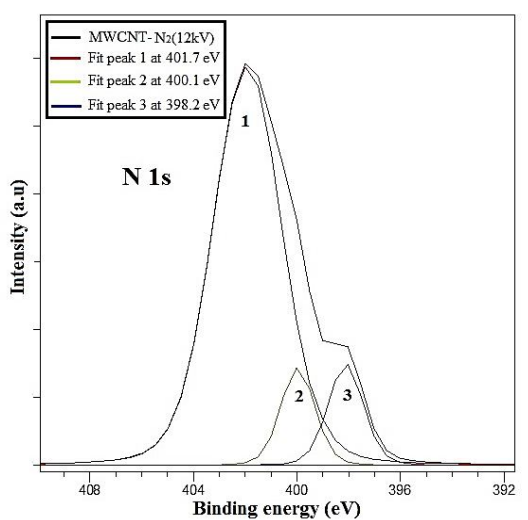

(a)

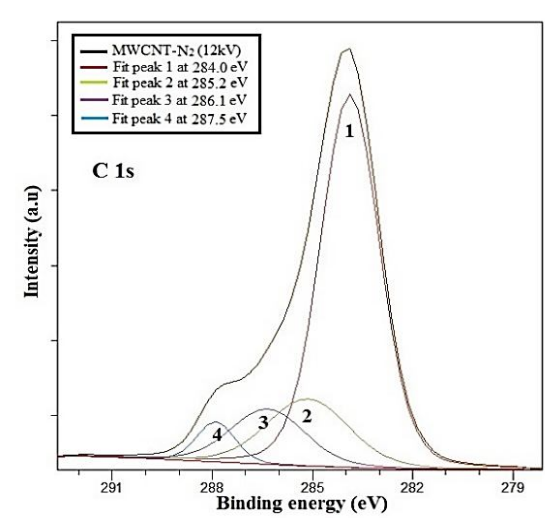

(b)

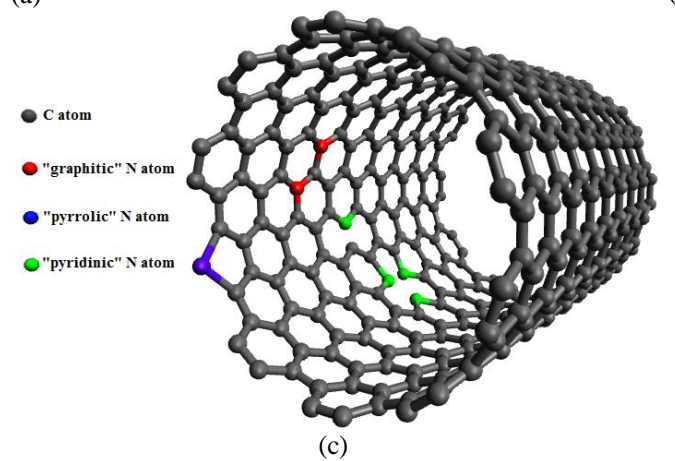

Figure 6: The XPS peak fitting for MWCNT-N $\mathrm{N}_{2}(12 \mathrm{kV}$ ) (a) N 1s and (b) C $1 \mathrm{~s}$.

(c) Schematic representation of N-doped CNT.

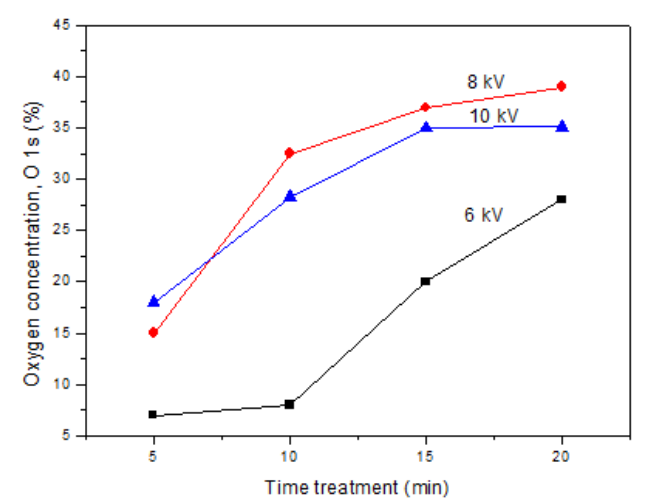

(a)

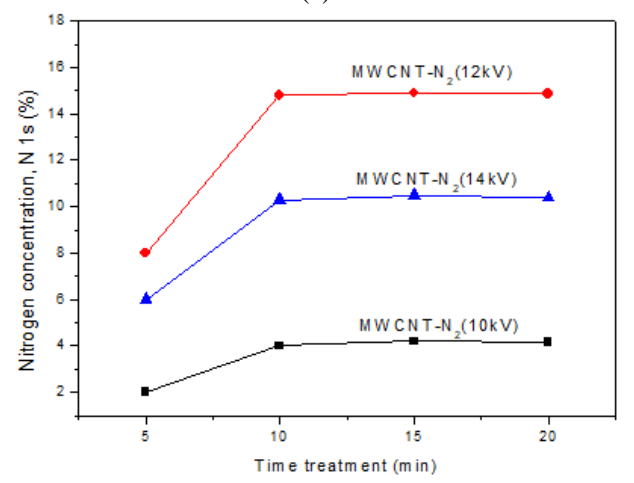

(b)

Figure 7: Variation of (a) Oxygen and (b) Nitrogen concentration with applied voltage at different time treatment
The concentration of nitrogen on MWCNTs at different applied voltage and time treatment is shows in Figure 7 (b). The higher concentration of nitrogen is happened when the applied voltage of plasma is at $12 \mathrm{kV}$. Dissimilar to Figure 7 (a), the concentration of nitrogen gives saturated values after 10 minutes of treatment time. It can be seen that, the optimum condition to functionalize higher concentration of nitrogen for DBD plasma at atmospheric pressure $(50 \mathrm{~Hz})$ is at $12 \mathrm{kV}$ applied voltage and 10 minutes time treatment.

\subsection{Electrical Characteristics}

Electrical characteristics of untreated and treated MWCNT using oxygen and nitrogen plasma was measured using current-voltage (I-V) measurement. The measurement of current-voltage characteristics was conducted at room temperature and within the biased voltage between $-5 \mathrm{~V}$ to $+5 \mathrm{~V}$. The measurement was repeated more than three times for each sample in order to validate the repeatability of the experiment. The I-V curve can measure the current flowing through the MWCNTs connected by the Al and Au electrodes as the function of voltage applied. Its behavior and performance as Schottky or Ohmic contact also can be examined from this measurement. Al was deposited to act as the rectifying contact and $\mathrm{Au}$ as the Ohmic contact to the channel [25]. In previous work, the combination of this 
asymmetric electrodes has been shown to rectify the current when a single SWCNT was contacted between them [37]. Our main purpose was to reach a similar rectifying behavior by using a treated MWCNTs network. Figure 8 shows a linear relationship between the current and voltage for MWCNTs-p. The linear graph demonstrates a resistive nature and no semiconducting characteristics can be identified and this Ohmic behavior is predictable since the MWCNTs-p is metallic in nature.

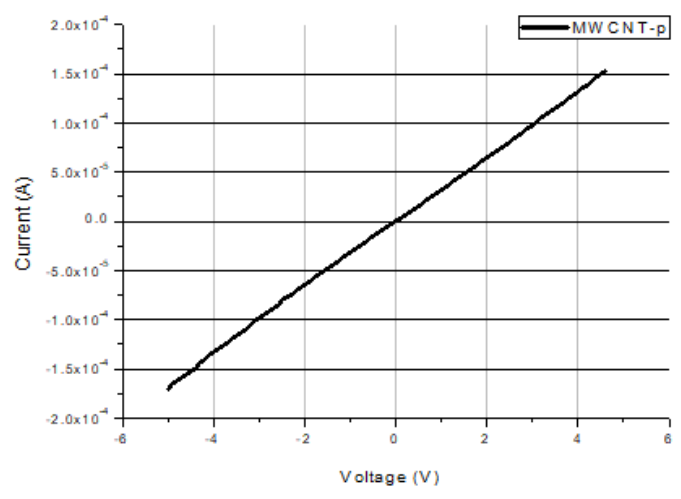

Figure 8: I-V curve for $\mathrm{Al} / \mathrm{MWCNTs}-\mathrm{p} / \mathrm{Au}$

Figure 9 (a) and (b) show the I-V characteristics for MWCNTs- $\mathrm{O}_{2}$ and MWCNTs- $\mathrm{N}_{2}$, respectively. In case of MWCNTs- $\mathrm{O}_{2}$, both I-V curves for $6 \mathrm{kV}$ and $8 \mathrm{kV}$ input voltages continued to act as Ohmic behavior. But, the resistance for $\mathrm{MWCNT}^{-\mathrm{O}_{2}}(8 \mathrm{kV})$ improved as compared to that of MWCNTs- $\mathrm{O}_{2}(6 \mathrm{kV})$. When input voltage of plasma was increased to $10 \mathrm{kV}$, the I-V curves for MWCNTs- $\mathrm{O}_{2}$ showed non-linear characteristics and tended to show near-Schottky behavior. Their electronics properties strongly affected by the severe defect structure of the MWCNTs. It can be noticed by the non-linear characteristics for MWCNTs- $\mathrm{O}_{2}$ treated at higher plasma voltage, where the higher energy of ion bombardment breaks the $\mathrm{C}=\mathrm{C}$ bond of MWCNTs. Unlike to MWCNTs- $\mathrm{O}_{2}$, all I-V curves for MWCNTs- $\mathrm{N}_{2}$ showed non-linear behaviors. The I-V curves showed rectifying or Schottky-like behavior from when the breakdown in nitrogen gas started to occur at $10 \mathrm{kV}$, until the discharge stopped at $14 \mathrm{kV}$. As can be observed, the current of MWCNTs- $\mathrm{N}_{2}(12 \mathrm{kV})$ was very small at lower bias, but went up after a slightly higher bias. This shown that the MWCNTs- $\mathrm{N}_{2}(12 \mathrm{kV})$ had a semiconducting character compared to MWCNTs- $\mathrm{N}_{2}(10 \mathrm{kV})$ and MWCNTs- $\mathrm{N}_{2}(14 \mathrm{kV})$. The behavior of current rectifying for $\mathrm{Al} / \mathrm{MWCNTs} \mathrm{N}_{2}(12) / \mathrm{Au}$ device is similar to SWCNTs based Schottky diode [25-28]. This suggested that with moderation of nitrogen plasma applied voltage, bamboo-like structure of MWCNTs would be created. This structure could increase the mobility of metallic MWCNTs, besides having the tendency to convert metallic MWCNT into semiconducting behavior. From these two different I- $\mathrm{V}$ curve behaviors of MWCNTs- $\mathrm{O}_{2}$ and MWCNTs- $\mathrm{N}_{2}$, it can be assumed that the nitrogen functional groups attached to the sidewall of the MWCNTs are greatly affect the electronic properties of MWCNTs compared to the oxygen molecules.

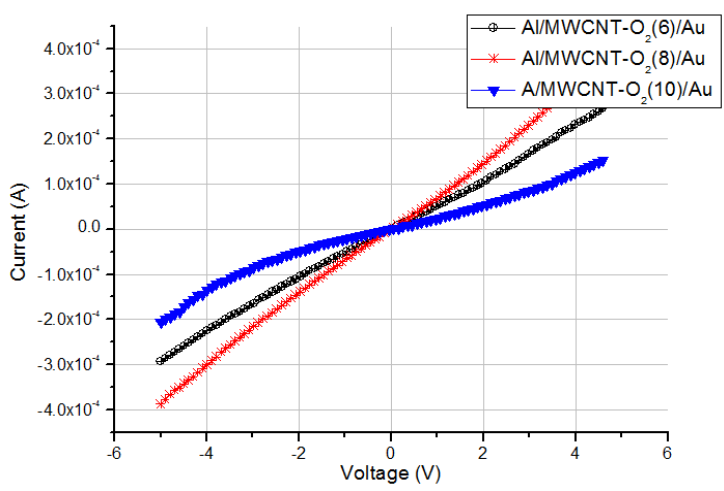

(a)

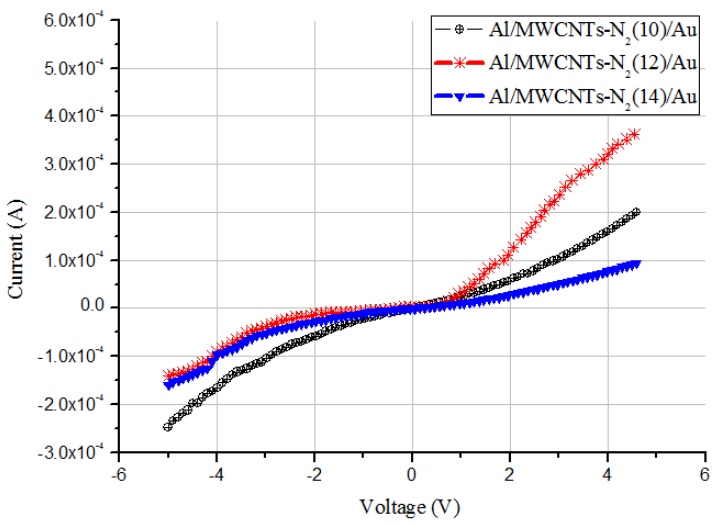

(b)

Figure 9: $\mathrm{I}-\mathrm{V}$ curve of (a) $\mathrm{Al} / \mathrm{MWCNTs}-\mathrm{O}_{2} / \mathrm{Au}$ and (b) $\mathrm{Al} / \mathrm{MWCNTs}-\mathrm{N}_{2} / \mathrm{Au}$.

Since $\mathrm{Au} / \mathrm{MWCNTs}-\mathrm{N}_{2}(12) / \mathrm{Al}$ is the optimum device that has current rectification similar to the previous research of SWCNTs based Schottky diode, the I-V data obtained was extracted to find their Schottky diode parameters. The quality of the diode can be evaluated by its parameter such as ideality factor $(n)$, saturated current (Io), barrier height $(\varnothing b)$, and series resistance $(R s)$ which measured from low forward bias part of $\ln (\mathrm{I})-\mathrm{V}$ characteristics and diode equation.

$I=I_{o}\left[\exp \left(\frac{q V}{n k T}\right)-1\right]$

Where $I_{o}$ is the saturation current, $q$ the elementary charge, $V$ the applied voltage, $k$ the Boltzmann constant and $\mathrm{T}$ is the absolute temperature. $I_{o}$ is the saturation current and can be expressed as:

$$
I_{o}=A A^{*} T^{2} \exp \left(\frac{-q \phi_{b}}{k T}\right)
$$

Where $A$ is a device area, $A *$ is effective Richardson Constant (120 $\mathrm{Acm}^{-2} \mathrm{~K}^{-2}$ for CNT [29]), $\varnothing_{\mathrm{b}}$ is the effective barrier height and $k$ is the Boltzmann constant. The ideality factor (n) of Schottky diode is calculated from the slope of linear region in ln I-V characteristics. It can be expressed as: 
$n=\left[\frac{q}{k T}\right]\left[\frac{d V}{d(\ln I)}\right]$

Whereas, the barrier height can be obtained from (2) as:

$$
\phi_{b}=\frac{k T}{q} \ln \left(\frac{A A^{*} T^{2}}{I_{o}}\right)
$$

Figure 10 shows the $\ln$ (I)-V plot for Al/MWCNTs- $N_{2}(12) / A u$. Low forward bias part of $\ln (\mathrm{I})-\mathrm{V}$ characteristics was used to measure $n$ and $\emptyset_{b}$, since the current curve in forward bias become dominated by series resistance and deviates from linearity. Taking natural logarithm of (1):

$$
L n I=L n I_{o}+\frac{q}{n k T} V
$$

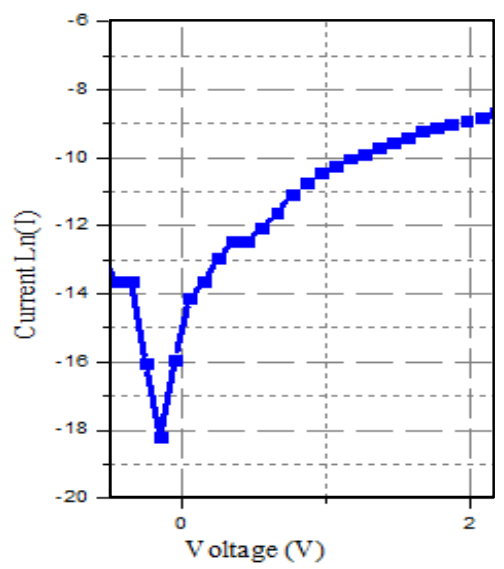

Figure 10: $\mathrm{Ln}(\mathrm{I})-\mathrm{V}$ plot for $\mathrm{Al} / \mathrm{MWCNTs}-\mathrm{N}_{2}(12) / \mathrm{Au}$

The value of $n$ and $I_{o}$ were determined from the slope and the $y$-axis intercept of the fitted straight line after performing least square fitting on the $\ln (\mathrm{I})-\mathrm{V}$ plot in the linear region as in Figure 11.

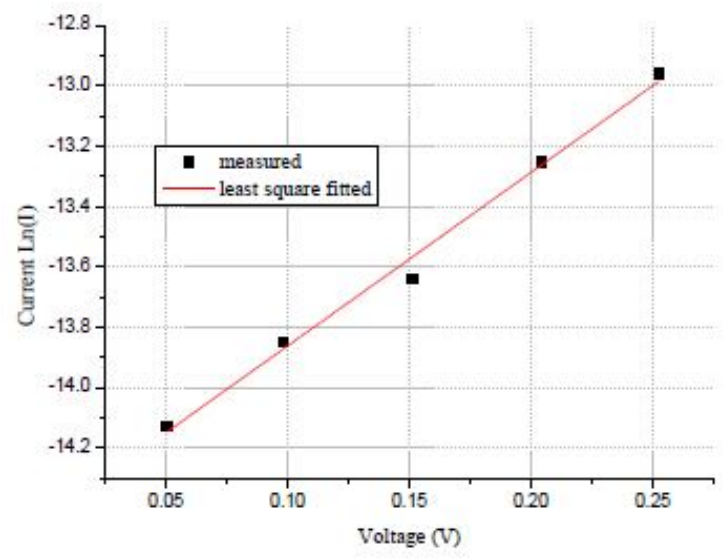

Figure 11: Least square fitting for ln I vs. V plot of $\mathrm{Au} / \mathrm{MWCNTs}_{\mathrm{N}}(12 \mathrm{kV}) / \mathrm{Al}$ Schottky diode
Using equation $5, n, I_{o}$ and $\emptyset_{b}$ were determined to be 6.69 , $5.2925 \times 10-7 \mathrm{~A}$ and $0.761 \mathrm{eV}$ respectively. It is reported that the ideal value for Schottky diode ideality factor lies between 0 to 1 . High value of ideality factor, $n$ could be due to the occurrence of oxide layer, interfacial layer and imperfections. However, this method only applicable for Schottky diode with low series resistance which can be ignored in the low forward region of $\mathrm{I}-\mathrm{V}$ curve. Series resistance, $R_{s}$ is an important parameter that effect the electrical characteristics of Schottky diode. It can be obtained by using Cheung method.

The forward biased I-V characteristics of Schottky diode with series resistance due to thermionic emission can be expressed as Cheung's function [30]:

$$
\begin{aligned}
& \frac{d V}{d L n I}=n \frac{k T}{q}+I R_{s} \\
& H(I)=V-n \frac{k T}{q} \operatorname{Ln}\left(\frac{I}{A A^{*} T^{2}}\right) \\
& H(I)=n \phi_{b}+I R_{s}
\end{aligned}
$$

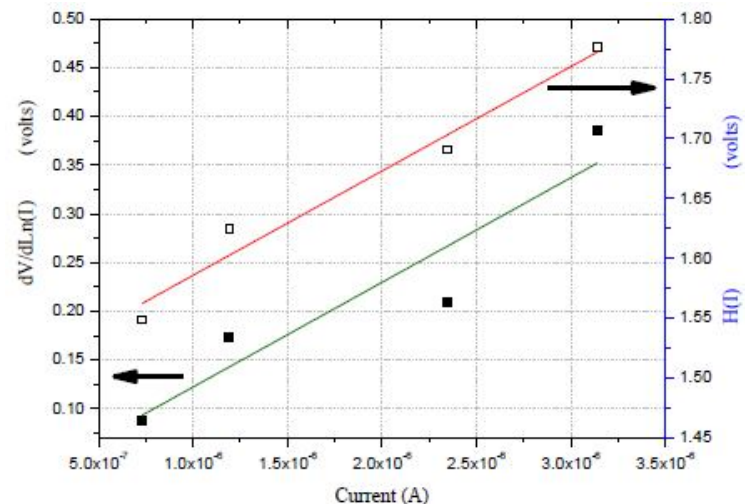

Figure 12: The dV/dLnI vs. I and $H(I)$ vs. I obtained from forward biased current-voltage characteristics of the Al/MWCNTs-N2(12kV)/Au Schottky diode

Figure 12 represents the $d V / d \operatorname{lnI}$ vs. I plot of $\mathrm{Au} / \mathrm{MWCNTs}-\mathrm{N}_{2}(12 \mathrm{kV}) / \mathrm{Al}$ Schottky diode. After fitting the curve using equation 6 , the values of $n$ and $R s$ can be obtained from the intercept and the slope of the line respectively. The value of $n$ obtained from $\mathrm{dV} / \mathrm{dln}$ I vs. I plot is 1.99 . This value of $n$ and $\mathrm{I}-\mathrm{V}$ data from experimental for $\mathrm{Au} / \mathrm{MWCNTs}-\mathrm{N}_{2}(12 \mathrm{kV}) / \mathrm{Al}$ are used to define $\mathrm{H}(\mathrm{I})$ based on equation 7. Plotting $\mathrm{H}(\mathrm{I})$ vs. I give a straight line as shown in Figure 12. According to equation 8 , the second values of $R s$ and $\emptyset_{\mathrm{b}}$ can be determined from its slope and y-axis intercept. The values of $R s$ obtained from $\mathrm{dV} / \mathrm{dLnI}$ vs. I and H(I) vs. I are $107.4 \mathrm{k} \Omega$ and $108.21 \mathrm{k} \Omega$ respectively. Thus, the value of $R s$ for Cheung's method is obtained from the average of these two values which is $107.81 \mathrm{k} \Omega$. 
An alternative method was proposed by Norde [31] in the determination the value of the series resistance. The equation of Norde's method is as follows:

$$
F(\mathrm{~V})=\frac{V}{\gamma}-\frac{k T}{q} \ln \left(\frac{I(V)}{A A^{*} T^{2}}\right)
$$

Where $\gamma$ is dimensionless which the first integer that have value greater than $n . I(V)$ is the value of current obtained from experimental data of $\mathrm{I}-\mathrm{V}$ curve. The value of barrier height can be obtained from equation (10) once the minimum of the $F$ vs. $V$ plot is determined:

$\phi_{b}=F\left(V_{o}\right)+\frac{V_{o}}{\gamma}-\frac{k T}{q}$

Where $F\left(V_{o}\right)$ is the minimum plot of $F(V)$, and $V_{o}$ is the corresponding voltage. The $F(V)$ vs $V$ plot of the junction is shown in Figure 13. The value of series resistance, $R_{s}$ can be determined from Norde's function by using the following relation:

$$
R_{s}=\frac{k T(\gamma-n)}{q I}
$$

From Norde's method, the values of $\Phi_{b}$ and $R_{s}$ of the structure have been obtained as $0.705 \mathrm{eV}$ and $110.85 \mathrm{k} \Omega$ respectively. The values of $\Phi_{b}, n$ and $R_{s}$ calculated by these three methods are tabulated in Table 2. It has been shown that Cheung's and Norde's methods give good agreement of series resistance and barrier height values. Large value of series resistance suggests that the mobility and free carrier concentration has decreased due to the presence of oxide layer at the interface. The first method (basic ln I-V) which omits the series resistance can cause to a large ideality factor. Thus, not including the series resistance can cause inaccuracy in calculating electrical parameters of the Schottky diode.

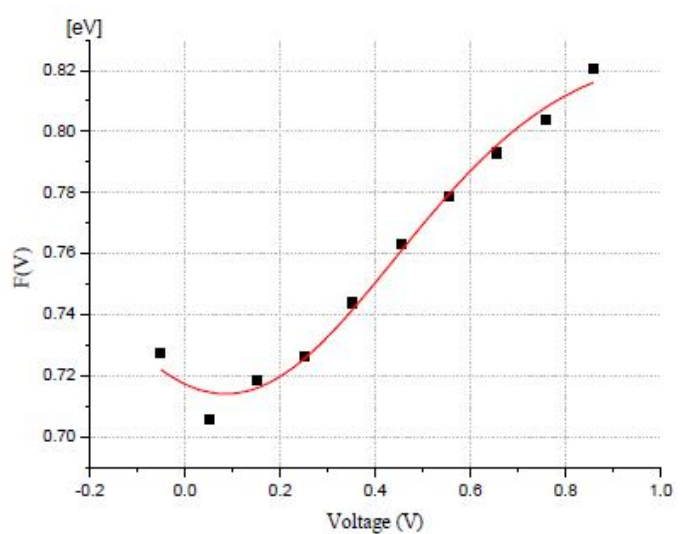

Figure 13: $\mathrm{F}(\mathrm{V})$ vs. V plot of the Al/MWCNTs-N2(12kV)/Au structure
Table 2: The electrical parameters obtained from I-V characteristics in three methods

\begin{tabular}{c|c|c|c}
\hline $\begin{array}{c}\text { Electrical } \\
\text { Parameter }\end{array}$ & $\begin{array}{c}\text { Barrier } \\
\text { Height }(\mathrm{eV})\end{array}$ & $\begin{array}{c}\text { Ideality } \\
\text { factor }(\mathrm{n})\end{array}$ & $\begin{array}{c}\text { Series } \\
\text { Resistance, } \mathrm{R}_{\mathrm{s}} \\
(\mathrm{k} \Omega)\end{array}$ \\
\hline Ln I-V & 0.761 & 6.695 & - \\
$\begin{array}{c}\text { Cheung's } \\
\text { method } \\
\text { Norde's } \\
\text { method }\end{array}$ & 0.753 & 1.99 & 107.81 \\
\hline
\end{tabular}

\section{CONCLUSION}

In this study, a method to convert metallic MWCNTs into semiconducting was successfully developed by introduced defects on MWCNTs surface by using atmospheric pressure dielectric barrier discharge (DBD) plasma treatment at $50 \mathrm{~Hz}$ (oxygen and nitrogen). It has been demonstrated that the applied voltages of non-thermal plasma generated by oxygen and nitrogen at atmospheric pressure can affect the surface and electrical properties after the modification process. It also can be proposed that the moderation plasma applied voltage) is necessary so that the functional group can attach to the sidewall of the MWCNT. Based on research finding, MWCNT modified by nitrogen at $12 \mathrm{kV}$ in 10 minutes treatment time give the optimum condition to convert linear I-V curve to rectification Schottky diode I-V curve. Additionally, Au/MWCNT(12)/Al has good rectification behaviour which give the ideality factor of 1.99 .

\section{ACKNOWLEDGEMENT}

The authors are gratefully acknowledge the funding provided by Universiti Tun Hussein Onn Malaysia and financial support from Ministry of Education Malaysia (Grant No R.J130000.7809.4F382).

\section{REFERENCES}

1. E. H. Rhoderick, Metal-semiconductor contacts, IEE Proceedings I-Solid-State and Electron Devices, vol. 129, p. 1, 1982.

2. Z. Ahmad and M. H. Sayyad, Extraction of electronic parameters of Schottky diode based on an organic semiconductor methyl-red Physica E: Low-dimensional Systems and Nanostructures, vol. 41, pp. 631-634, 2009.

3. Ş. Aydoğan, M. Sağlam, and A. Türüt, On the some electrical properties of the non-ideal $\mathrm{PPy} / \mathrm{p}-\mathrm{Si} / \mathrm{Al}$ structure, Polymer, vol. 46, pp. 10982-10988, 2005.

4. T. Uchino, F. Shimpo, T. Kawashima, G. Ayre, D. Smith, C. de Groot, et al., Electrical transport properties of isolated carbon nanotube/Si heterojunction Schottky diodes, Applied Physics Letters, vol. 103, p. 193111, 2013.

5. A. Choudhury and P. Kar, Doping effect of carboxylic acid group functionalized multi-walled carbon 
nanotube on polyaniline, Composites Part $B$ : Engineering, vol. 42, pp. 1641-1647, 2011.

6. L. Ding, A. Tselev, J. Wang, D. Yuan, H. Chu, T. P. McNicholas, et al., Selective growth of well-aligned semiconducting single-walled carbon nanotubes, Nano letters, vol. 9, pp. 800-805, 2009.

7. A. Di Crescenzo, V. Ettorre, and A. Fontana, Non-covalent and reversible functionalization of carbon nanotubes, Beilstein journal of nanotechnology, vol. 5, p. 1675, 2014.

https://doi.org/10.3762/bjnano.5.178

8. A. Bachtold, P. Hadley, T. Nakanishi, and C. Dekker, Logic circuits with carbon nanotube transistors, Science, vol. 294, pp. 1317-1320, 2001.

9. R. Krupke, F. Hennrich, H. v. Löhneysen, and M. M. Kappes, Separation of metallic from semiconducting single-walled carbon nanotubes, Science, vol. 301, pp. 344-347, 2003.

10. P. G. Collins, M. S. Arnold, and P. Avouris, Engineering carbon nanotubes and nanotube circuits using electrical breakdown, science, vol. 292, pp. 706-709, 2001.

11. M. Zheng, A. Jagota, M. S. Strano, A. P. Santos, P. Barone, S. G. Chou, et al., Structure-based carbon nanotube sorting by sequence-dependent DNA assembly, Science, vol. 302, pp. 1545-1548, 2003.

12. T. Tanaka, H. Jin, Y. Miyata, and H. Kataura, High-yield separation of metallic and semiconducting single-wall carbon nanotubes by agarose gel electrophoresis, Applied physics express, vol. 1, p. 114001, 2008.

13. S.-Y. Ju, M. Utz, and F. Papadimitrakopoulos, Enrichment mechanism of semiconducting single-walled carbon nanotubes by surfactant amines," Journal of the American Chemical Society, vol. 131, pp. 6775-6784, 2009.

14. C. Liu and H.-M. Cheng, Carbon nanotubes: controlled growth and application, Materials Today, vol. 16, pp. 19-28, 2013/01/01/ 2013.

15. M. S. Arnold, A. A. Green, J. F. Hulvat, S. I. Stupp, and M. C. Hersam, Sorting carbon nanotubes by electronic structure using density differentiation, Nature nanotechnology, vol. 1, pp. 60-65, 2006.

16. M. Scardamaglia, C. Struzzi, F. J. A. Rebollo, P. De Marco, P. R. Mudimela, J.-F. Colomer, et al., Tuning electronic properties of carbon nanotubes by nitrogen grafting: Chemistry and chemical stability, Carbon, vol. 83, pp. 118-127, 2015.

17. D. Janas, S. Boncel, A. A. Marek, and K. K. Koziol, A facile method to tune electronic properties of carbon nanotube films, Materials Letters, vol. 106, pp. 137-140, 2013.

https://doi.org/10.1016/j.matlet.2013.04.111

18. H.-Z. Geng, K. K. Kim, C. Song, N. T. Xuyen, S. M. Kim, K. A. Park, et al., Doping and de-doping of carbon nanotube transparent conducting films by dispersant and chemical treatment, Journal of Materials Chemistry, vol. 18, pp. 1261-1266, 2008.

19. S. Yaragalla, G. Anilkumar, N. Kalarikkal, and S. Thomas, Structural and optical properties of functionalized multi-walled carbon nanotubes, Materials Science in Semiconductor Processing, vol. 41, pp. 491-496, 2016/01/01/ 2016.
20. Z.-y. Zhang and X.-c. Xu, Wrapping carbon nanotubes with poly (sodium 4-styrenesulfonate) for enhanced adsorption of methylene blue and its mechanism, Chemical Engineering Journal, vol. 256, pp. 85-92, 11/15/ 2014.

21. J. Maiti, N. Kakati, S. H. Lee, and Y. S. Yoon, Fluorination of multiwall carbon nanotubes by a mild fluorinating reagent HPF6, Journal of Fluorine Chemistry, vol. 135, pp. 362-366, 3// 2012.

22. A. Miodek, N. Mejri-Omrani, R. Khoder, and H. Korri-Youssoufi, Electrochemical functionalization of polypyrrole through amine oxidation of poly(amidoamine) dendrimers: Application to DNA biosensor, Talanta, vol. 154, pp. 446-454, 7/1/ 2016.

23. L. G. Nair, A. S. Mahapatra, N. Gomathi, K. Joseph, S. Neogi, and C. P. R. Nair, Radio frequency plasma mediated dry functionalization of multiwall carbon nanotube, Applied Surface Science, vol. 340, pp. 64-71, 6/15/ 2015.

24. H. M. Manohara, E. W. Wong, E. Schlecht, B. D. Hunt, and P. H. Siegel, Carbon nanotube Schottky diodes using Ti- Schottky and Pt- Ohmic contacts for high frequency applications, Nano letters, vol. 5, pp. 1469-1474, 2005.

25. B. Hicks, S. Getty, and D. Allred, Diode properties of nanotube networks, Thin Solid Films, vol. 518, pp. 5014-5017, 2010.

26. L. Huang, E. F. Chor, Y. Wu, and Z. Guo, Fabrication of single-walled carbon nanotube Schottky diode with gold contacts modified by asymmetric thiolate molecules, Carbon, vol. 48, pp. 1298-1304, 2010.

27. M. Yang, K. Teo, W. Milne, and D. Hasko, Carbon nanotube Schottky diode and directionally dependent field-effect transistor using asymmetrical contacts, Applied Physics Letters, vol. 87, p. 253116, 2005.

28. C. Lu, L. An, Q. Fu, J. Liu, H. Zhang, and J. Murduck, Schottky diodes from asymmetric metal-nanotube contacts, Applied physics letters, vol. 88, p. 133501, 2006.

29. P. Liu, Y. Wei, K. Jiang, Q. Sun, X. Zhang, S. Fan, et al., Thermionic emission and work function of multiwalled carbon nanotube yarns, Physical Review B, vol. 73, p. 235412, 2006.

30. S. Cheung and N. Cheung, Extraction of Schottky diode parameters from forward current-voltage characteristics, Applied Physics Letters, vol. 49, pp. 85-87, 1986.

31. H. Norde, A modified forward I-V plot for Schottky diodes with high series resistance, Journal of Applied Physics, vol. 50, pp. 5052-5053, 1979.

https://doi.org/10.1063/1.325607 